\section{Da reforma psiquiátrica à luta pela 'vida não-fascista'}

\section{From psychiatric reform to the struggle for a 'non-fascist life'}

\section{Sergio Alarcon}

Secretaria Estadual de Ação Social, Rio de Janeiro Av. Almirante Álvaro Alberto, 180/1101 22610-070 Rio de Janeiro - RJ Brasil

alarcon@cremerj.com.br
ALARCON, S.: Da reforma psiquiátrica à luta pela 'vida não-fascista'.

História, Ciências, Saúde - Manguinhos, v. 12 , n. 2 , p. $249-63$, maio-ago. 2005

Este artigo procura decifrar a reforma psiquiátrica a partir da suposição de que em seu bojo convivem determinações teóricopráticas distintas, ora associadas, ora concorrentes. De início, abordamos a questão de forma conceitual. Posteriormente, um breve histórico procura resgatar as motivações emancipatórias da reforma. Por fim, sustentamos uma pequena análise sobre essas determinações, com o intuito de iniciar um debate quanto às modificações estratégicas que o movimento deve empreender para evitar retrocessos em suas práticas.

PALAVRAS-CHAVE: saúde mental; reforma psiquiátrica; clínica política.

ALARCON, S.: From psychiatric reform to the struggle for a 'non-fascist life'.

História, Ciências, Saúde - Manguinhos, v. 12, n. 2, p. 249-63, May-Aug. 2005.

This effort to decipher psychiatric reform starts from the supposition that the reform contains within itself distinct theoretical-practical determinations, at times associated, at times competing. We begin by addressing the issue from a conceptual standpoint, from there moving to a short historical overview that seeks to uncover the emancipatory motivations underlying the reform. Lastly, these determinations are analyzed in brief, our purpose being to initiate a debate about the strategic changes that the movement should enact if it is to avoid retrogression in its practices.

KEYWORDS: mental health; psychiatric reform; political clinical practice. 
... a medida desmesurada da distância que se abre e desenha o traço que faz descobrir os limites de suas próprias formas.

Michel Foucault

$\mathrm{D}$

evemos lembrar que o momento histórico em que estávamos quando se iniciaram as discussões para a reforma psiquiátrica - entre as décadas de 1960 e 1970 - era de turbulência política, com uma ditadura militar instalada, uma resistência armada sendo dissipada, e uma resistência ética em construção. Muitos reconhecem no caráter combativo do movimento pela reforma psiquiátrica e na luta antimanicomial um sintoma da politização inerente ao período. Alguns trabalhos produzidos nessa época tentam, de forma bastante objetiva, ligar a psiquiatria às formas de dominação construídas pelo Estado (como o famoso texto de Serra, 1981).

Em parte, não podemos refutar essa tese. Contudo, consideramos revolucionário, não a aberta recusa ao modelo psiquiátrico, mas sua problematização. Afirmar o desvio moral do modelo, a necessidade de um retorno aos seus ideais, o melhoramento de seu aparato assistencial, sua humanização, assim como simplesmente propor o fim da psiquiatria tout court, nos parece ainda um saudosismo do tipo platônico, uma crença no modelo que, degenerado, deve ser reconstituído à sua forma original e plena; ou uma crença na verdadeira subjetividade detrás da loucura institucionalizada.

A questão principal a ser colocada sempre foi de ordem ética e não apenas epistemológica; de ordem micropolítica e não simplesmente de tomada de poder. Mesmo porque, ver a psiquiatria apenas como um aparelho ideológico (usando o termo na acepção de Althusser, 2001) seria, em última análise, absolvê-la, de antemão, de uma problematização mais profunda. Um risco que, na verdade, ainda é nosso. A luta atual nesse campo se faz nos interstícios entre uma espécie de moralismo político-epistemológico, que derruba um ídolo, mas mantém seu lugar, e uma problematização ético-política, que pretende transformar a realidade ao nos transportar para além do que somos.

Tentamos também deixar delineada, neste texto, a tese de que a reforma psiquiátrica no Brasil tem se dado, assimetricamente, conforme idéias distintas, mas associadas e sincrônicas - determinadas, respectivamente (conforme nosso referencial teórico foucaultiano), por uma ontologia formal (para as críticas políticoepistemológicas da psiquiatria) e uma estética da existência (para as problematizações de cunho ético-político).

Apesar de reconhecermos o caráter dinâmico dos processos, afirmamos que, por ser hegemônica, o sucesso da ontologia formal corre o risco de sufocar ou minimizar a necessidade de um ponto de vista prático que leve em conta a estética da existência. Ao pro- 
por essa hipótese diagnóstica, salientamos que talvez tenha chegado a hora de se inverter tal determinação.

Permeando o texto de forma implícita, procuramos evidenciar nossa recusa em considerar mais detalhadamente as questões moralistas que impregnaram algumas análises do período e suas conseqüências até aqui. Consideramos tais análises superficiais especialmente por não serem capazes de distinguir, a não ser através do recurso óbvio do dicionário vernacular, o conceito de 'micropolítica' - considerado invariavelmente como o nome indica, uma política menor - do de 'política'; ou mesmo confundi-lo para enfatizar uma suposta oposição à idéia de macropolítica. Veremos por que não interpretamos esse conceito nem como uma política menor (no sentido lato), nem com base em uma oposição à macropolítica. Pelo contrário, achamos que é exatamente a partir das políticas 'menores' (como na luta entre 'loucura' e 'manicômio') que podemos alcançar a verdadeira transformação macropolítica.

\section{Ontologia das forças e ontologia formal}

Procurando esclarecer as diferenças fundamentais entre ontologia formal e estética da existência, buscamos resumir nosso entendimento conceitual do problema. Nossa hipótese é a de que a dicotomia que marca uma certa disputa contemporânea na saúde mental se resume a esses dois modos de se entender a realidade, e, por conseguinte, a duas maneiras éticas, políticas e epistemológicas de se conceber a reforma psiquiátrica. Por um lado, identificamos uma perspectiva tributária da tradição de pensamento que vem de Kant a Marx e Freud, e de outro a linha que começa em Nietzsche, e se desenvolve com Foucault, Deleuze e Guattari.

Foucault fundamenta sua idéia de realidade com base nas noções de saber e poder. Grosso modo, Foucault entende o saber como um conjunto de práticas discursivas e não discursivas que tecem as condições para as atividades úteis à manutenção de nosso cotidiano. Por poder Foucault concebe um exercício que não apenas reprime ou censura, mas que principalmente estimula nos indivíduos a produção de suas almas, idéias, moral e saber. Saber e poder não estão separados, como tradicionalmente se pensa: as relações de poder supõem como correlato um campo de saber, e não há saber sem o pressuposto e a constituição, ao mesmo tempo, de relações de poder. (Foucault, 1975).

Essa concepção de mundo percebe a realidade bifurcada em duas vias entrelaçadas e inseparáveis. Fazendo um paralelo com a história da filosofia, chamaremos essas duas vias de formal e material, associando o mundo formal ao saber, e o mundo material ao poder. A realidade para Foucault não se fundamenta em idéias puras (como o sujeito transcendental kantiano) nem em verdades teológicas 
(como nas teses transcendentes), mas em uma univocidade imanente, portadora de um duplo causal. Quanto a esse tipo de causa abordada por Foucault, podemos chamá-la de 'exemplar'. Segundo André Lalande (1999), a causa exemplar é um "modelo concebido pelo espírito como um ideal artístico e conforme ao qual a causa eficiente produz o seu efeito" (p. 361). O exemplarismo foucaultiano supõe que as formas são produzidas segundo relações de forças, e que cada força da relação procura imprimir na outra o seu sentido hegemônico, isto é, o 'poder'. Poder para Foucault é um efeito de relações, cuja forma (saber) é a expressão (o ver e o dizer) de um conjunto complexo no qual uma força comanda, induz, dá sentido e valoriza outras forças, extraindo dessas forças 'dominadas' o que nelas lhe interessa como meio de auto-afirmação. Por isso o poder é positivo, produtivo, sendo a hipótese repressiva (do poder como aquilo que essencialmente reprime - tese que sustenta a psicanálise e o marxismo) algo sem sentido para uma analítica dos problemas (das relações de forças), apesar de plenamente observável na dimensão formal (os saberes) da realidade.

Chamamos ontologia formal a todo pensamento que privilegia análises circunscritas ao saber, não se preocupando, portanto, com a dimensão do que Foucault chama poder. Utilizamos a palavra 'ontologia' - o termo surge no século XVII e se refere ao estudo sobre o fundamento da ordem das coisas - para reforçar a idéia de que se trata de um tipo de pensamento que possui pretensão totalizadora, mas que acaba restrita a uma das 'metades' da realidade, o que torna o seu efeito paradoxal quando em confronto com um pensamento que privilegia as já citadas dimensões da mundanidade. Para melhor compreensão do que queremos dizer, podemos aproximar a ontologia formal do que Kant (1987) denomina como a 'crítica', cuja função é justamente estabelecer as condições de possibilidades formais (a competência), mas nunca a razão de ser da própria forma (o fundamento). Assim, a Crítica da razão pura, por exemplo, nada mais é que um tribunal onde a instância formalizadora (a razão) julga a própria legitimidade de sua competência, isto é, ser capaz de construir objetos de conhecimento. Uma ontologia formal se faz, então, quando a instância formalizadora se volta sobre si mesma para estabelecer os limites de sua capacidade de formalizar, isto é, estabelecer definições sobre si mesma. No caso de Kant, estando as formas no sujeito do conhecimento, trata-se, mais amiúde, de uma ontologia do sujeito.

De modo diferente, a problematização foucaultiana não trataria apenas das formas em si mesmas, de seus limites legítimos ou de suas condições de possibilidade, mas associaria a existência do mundo formal a motivações profundas contidas nas relações entre forças que constituem um poder e que dão sentido 'existencial' ao mundo das formas (dos saberes). Seguindo a lógica do exemplo 
citado, em Foucault poderíamos falar de uma ontologia das relações entre forças.

Ao desprender-se da idéia de que haveria uma separação entre poder e saber, Foucault cria o binômio unívoco poder/saber, e se vê obrigado a pensar em uma nova concepção de sujeito, diferente da kantiana, como um terceiro eixo (junto com o saber e o poder) para a inteligibilidade do real. É sobre isso que falaremos a seguir.

\section{Estética da existência e micropolítica (ou como não desejar aquilo que nos domina e explora)}

Para entendermos o que Foucault quer ao falar de uma estética da existência devemos antes indicar o lugar onde o autor se situa na história da ética e que o liga claramente ao problema da liberdade (entendendo-se a liberdade como o horizonte de qualquer ética desde, pelo menos, Kant).

Podemos dizer que há três grandes temas sobre a liberdade: o tema da dominação (de um povo sobre outro, de uma religião sobre outra, de uma opção sexual sobre outra, e assim por diante); o tema da exploração (do capital sobre o trabalho); e o tema da sujeição (a produção de subjetividade). O kantismo e, posteriormente, o hegelianismo e o marxismo não conseguiram chegar a problematizar o tema da sujeição, pois pensaram em termos, primeiro, de uma natureza humana e, segundo, de repressão, ideologia e alienação dessa natureza. A linha de pensamento foucaultiana refuta a tese de um sujeito prévio às condições mundanas e, ao pensar os processos de produção de subjetividade, não utiliza como pressuposto - e isso já foi aqui salientado - a chamada hipótese repressiva (não haveria propriamente uma essência humana a ser reprimida), mas a positividade resultante de tecnologias de produção (Foucault, 1990). Nessa concepção, o homem não é considerado como guardando no seu íntimo uma 'verdade-em-si', uma natureza pronta cuja expressão poderia ser obnubilada ou falseada pelas ideologias ou recalques. O homem, como diz Nietzsche (1994), é uma corda entre o animal e o além-do-homem, ou seja, é um processo não teleológico (de superação de si), é virtualidade, e a atualização dessa virtualidade se dá através de estímulos provenientes das relações de poder/saber de cada época. Pode-se dizer com isso que somos meros efeitos de nossa época, ou seja, somos 'assujeitados' aos poderes estabelecidos. É nesse sentido 'positivo' (de produção de subjetividades) que Foucault utiliza o termo sujeição. Só que essa luta não é propriamente 'contra' a sujeição, pois todos têm que se assujeitar em certo sentido, ou melhor, todos adquirem subjetividade nas relações necessárias com a mundanidade.

Luta-se, contudo, para 'ultrapassar' a sujeição; uma luta contínua, perene, que se faz resistindo aos poderes miúdos, isto é, dife- 
rentes daquele que se concentra nas formas jurídicas do Estado, mas que o sustentam de forma sub-reptícia na trama das pequenas relações do dia-a-dia. São as chamadas lutas micropolíticas ou transversais. Luta, por exemplo, da mulher para ultrapassar sua sujeição ao homem (pois o machismo não acontece quando o homem se impõe à mulher, mas quando os processos de individuação da mulher se fazem a partir de uma concepção de virilidade); do louco para ultrapassar sua sujeição ao sistema médico-psicológico (pois a noologia psiquiátrica cria o 'sujeito asilado', socialmente excluído); do dependente químico para ultrapassar sua sujeição ao tráfico (pois é a 'lógica do trafico' que criminaliza o usuário e moraliza a droga).

A idéia de emancipação de Kant a Foucault muda, deixa de ser sustentada por uma entidade metafísica clássica (a liberdade em si), e se transforma naquilo que constantemente conquistamos ao ultrapassarmos cada milímetro de sujeição. Não havendo um sujeito natural prévio às relações mundanas, emancipar-se significa exercer uma resistência às duas formas atuais de sujeição: a que nos individualiza de acordo com as exigências do poder (poder entendido como um efeito de relações de forças 'imanentes' - no nosso caso contemporâneo, o biopoder), e a que consiste em ligar cada indivíduo a uma identidade determinada e imutável.

A luta pela subjetividade se apresenta então como estética da existência, uma maneira ao mesmo tempo ética e política de estar no mundo como o artista de si mesmo, conquistando a cada instante o direito à diferença e à metamorfose. Se podemos chamar sujeição àquilo que, de forma prosaica, denominamos consciência, então a emancipação é, assim, um processo por meio do qual ultrapassamos a nós mesmos.

\section{Negação e contra-discurso}

Tentaremos agora nos orientar pelo itinerário da reforma em suas lutas emancipatórias, sempre permeada ou por uma ontologia formal ou pelas questões da estética da existência.

Como afirmei há pouco, a reforma psiquiátrica no Brasil se iniciou em plena época de exceção, quando todos os discursos públicos eram reduzidos à emanação do Estado ditador. Contudo, em um mundo onde não há uma autoridade regendo o discurso, onde a palavra de ordem (mágico-religiosa ou moral) do déspota foi superada pelo diálogo público - pela chamada palavra-diálogo (Detienne, 1988) -, toda proposição produzida, seja afirmativa ou negativa, pode ser discutida, refutada, defendida.

Esse jogo dialógico reflete uma diferença com o mundo da tirania, no qual a censura, os atos institucionais, os aparelhos repressivos ou ideológicos do Estado suprimem toda separação temporal 
necessária entre a deliberação e a ação correspondente. Na tirania, toda palavra coincide com a ação que institui o campo social. A palavra-diálogo é, ao contrário, "uma palavra que precede à ação humana, que é seu complemento indispensável" (Detienne, 1988, p. 51).

Por essa distinção, podemos dizer que um dos índices da superação de um estado de tirania seja o aparecimento da palavra como um bem comum - uma coiné - e a possibilidade de o indivíduo expressar-se em situação de igualdade e reciprocidade, conjugando teses, defendendo-as, fazendo-as ganhar aliados, potencializandoas até transformá-las em ação.

Devemos observar que, em relação à reforma psiquiátrica, antes de empreender um esforço a favor de uma solução para questões específicas dos interesses de seu objeto, sua aparição se liga à conquista do direito de existir como antítese do discurso representado pela psiquiatria e, por extensão, pelo Estado (Serra, 1981). É, portanto, o direito à negação que em primeiro lugar motiva a reforma psiquiátrica no Brasil. Esse direito, além de implicar algo a ser negado, a escolha do que negar, o alvo sobre o qual o maior peso dessa negação deve recair, significa antes 'apenas' o poder de negar. Por evidente condição sine qua non, essa negação teve que ser dirigida, sobretudo, contra o regime político ditatorial do país. O movimento pela reforma psiquiátrica no Brasil foi, por isso, um dos movimentos contra a dominação política mais longos, inventivos e bemsucedidos de nossa história. Expressou-se na capacidade coletiva de inserir, no seio de um contexto social - mesmo o constituído por palavras de ordem, iniqüidades, violência explícita - o pressuposto de qualquer discurso prepositivo: a refutação. Foi assim que, lentamente, a luta contra o modo 'manicomial' de tratar a loucura se transformou também em uma prática contra-discursiva no seio daquilo que por definição não permite o diálogo.

\section{A estética da autolimitação}

Se, como afirma Roland Barthes (2001), o discurso é a manifestação concreta da linguagem - oral ou escrita - em seu poder de referenciar o mundo, então nos é legítimo perguntar se um contradiscurso não seria o calar-se, o silêncio que nega qualquer expressão da palavra e, nesse caso, a afirmação de um mundo cujo sentido era a palavra de ordem. Sobre isso, Barthes, na obra Sade, Fourier, Loyola (1971), define como contra-discurso não a ausência da palavra, mas a palavra que, voltando-se sobre si mesma - como numa auto-reflexividade - não mais se dirige às coisas.

Nesse aspecto, podemos aproximar as práticas iniciais da reforma psiquiátrica no Brasil - em especial as histórias que Paulo Amarante et al. (1998) nos contam sobre a 'crise na Dinsam' (Divisão 
Nacional de Saúde Mental) e o Movimento dos Trabalhadores de Saúde Mental (MTSM) até, pelo menos, o congresso de Bauru e o surgimento do movimento da luta antimanicomial - como etapas de um processo contra-discursivo que, ultrapassando as lutas propriamente militantes hostis à ditadura em particular, voltou-se sobre si mesmo e tomou-se como objeto num processo destinado a avaliar os limites de suas próprias condutas, cujo cotidiano se mostrava insuportável.

A reforma psiquiátrica no Brasil realizou aquilo que Foucault (2001) coloca como a experiência trágica, isto é, a experiência da descoberta dos próprios limites - uma prática da ontologia formal - que antes de se preocupar com a relação de adequação semântica e metafísica entre as palavras e as coisas, entre as coisas e seus significados - como entre o doente e sua doença -, faz um retorno sobre si mesmo para libertar-se de seu sentido como representação das palavras de ordem que, nos termos que nos interessam aqui, constituem os liames de uma disciplina e o comportamento quase estereotipado de seus técnicos especialistas.

No caso da reforma esse estabelecimento de limites se resumiu na construção de conexões para além do que estava interditado pelo modelo psiquiátrico em sua existência obediente a uma ordem dada e pelo qual determinava a condição heterônoma do homem louco. Significou aos trabalhadores da Saúde Mental e aos loucos uma inusitada união capaz de transgredir a existência ordinária a partir de suas próprias determinações. Em termos políticos, para Bauman (2000), trata-se de uma forma especial de arte - a democracia - capaz de "desmontar os limites à liberdade dos cidadãos" (p. 12) para capacitá-los a traçar, individual e coletivamente, seus próprios limites individuais e coletivos em uma espécie de 'estética' da autolimitação. Na crítica epistemológica efetuada pela reforma psiquiátrica, tratou-se de questionar o direito da psiquiatria em dizer a verdade sobre a loucura. Por isso, podemos afirmar que o efeito do contra-discurso na reforma psiquiátrica buscou, além de empreender uma luta contra a dominação política, construir sobre si mesmo o extraordinário, ou, na fala de Foucault (2001, p. 33) a "medida desmesurada da distância que se abre e desenha o traço que faz descobrir os limites de suas próprias formas".

O termo 'extraordinário' refere-se ao efeito de tudo aquilo ou àquele que se arrisca ao 'julgar' seus limites 'ordinários', adquiridos e admitidos sem crítica. Algo que, no entanto, obviamente, e para lá das questões macropolíticas, causou hesitação e contrariedade, pois o extraordinário se aproxima da própria loucura para o indivíduo acostumado à ordem hierarquizada proveniente da heteronomia. Uma loucura negada avidamente pelo homem médio, a quem os psicanalistas denominam 'neurótico'. A reforma psiquiátrica caminhava assim, de luta em luta, da macro à micropolítica. 


\section{Neurose e perversão (o risco do fascismo que está em cada um de nós)}

É neurótico, justamente, aquele incapaz de tolerar a própria perversão ou o inominável que acompanha a novidade (Deleuze \& Guattari, s.d., p. 38-9). Por isso o neurótico não só se subordina a tudo que seja 'nomeável' ou familiar, mas acredita e deseja a subordinação. É aquele que, no limite entre o conforto e o sofrimento, clama por um diretor de consciência ou um coronel que lhe diga como se comportar. Para falar politicamente: é o ovo da serpentea condição do fascismo.

Mas os neuróticos têm suas razões: não é possível para qualquer um suportar a novidade, viver nela e por ela. Sempre queremos - e com muita justiça diante de toda nossa fragilidade - o familiar, o antecipadamente definível, o certo e seguro. Em outras palavras: a repetição. Além disso, é fácil entender que não podemos viver sem a crença na repetição. Acreditar, por exemplo, que a água sempre vai matar a sede é um quantum satis que torna possível a sobrevivência. Mas, se a reforma psiquiátrica conseguiu forças para expandir-se, mesmo no seio da repressão política, foi - e isso deve ser entendido mais em termos de experiência vital do que apenas intelectualmente - a partir da crença de que a vida é justamente o poder de ultrapassar a repetição; de que esta é, por assim dizer, sua essência.

Henri Bergson, filósofo francês falecido em 1941, diz que o espírito - apelido que dá à vida, sem nenhuma conotação religiosa - é pura diferença, ou seja, é sempre novidade. A vida injeta no seio da matéria repetitiva, senil e monótona, a frescura do novo (Bergson, 1990). Diz-se, por esse motivo, que quando um amor acaba é porque deixou de ser espiritualizado, tornou-se repetição mecânica, rotina e tédio. Isso explica querermos quase compulsivamente justificar nossos afetos não por eles mesmos, mas por qualquer coisa de transcendente: corriqueiramente cremos que um casamento já sem razão de ser deve ser mantido pelos filhos ou pelas aparências; que um trabalho insuportável vale o sacrifício pelo salário ou pela aposentadoria; que devemos ler o último best seller porque, afinal, está na moda, é fácil de entender e mata o tempo. Aliás, 'matar o tempo' é a expressão mais incrível de nossa modernidade; não resta outra coisa a fazer se a maior parte da vida é tediosa.

Ainda que alguém (como Bergson) nos lembre que 'tempo' pode ser um eufemismo para 'vida', teimamos em supor (com variações) haver uma vida do 'além' para legitimar o tédio e nos fazer deixar tudo para depois (de mortos?). É assim que, de certa maneira, nosso cotidiano não parece ser tão diferente do que acontece entre as paredes dos manicômios. 
Não é, portanto, unicamente com base em ações voltadas contra o Estado ou a favor de um contexto epistemológico 'mais adequado' que podemos exercer uma resoluta resistência que poderíamos chamar antifascista, na medida em que foi no fascismo que descobrimos a máxima potência do que Hanna Arendt (1999) chamou a 'banalidade do mal'. Como afirma Foucault (1996, p. 199), não basta mais estarmos alertas apenas contra

o fascismo histórico de Hitler e Mussolini - que soube tão bem mobilizar e utilizar o desejo das massas - mas também o fascismo que está em todos nós, que assombra nossos espíritos e nossas condutas cotidianas, o fascismo que nos faz amar o poder, desejar esta coisa mesma que nos domina e nos explora.

\section{O abismo para além dos limites}

Provavelmente eu tenha de ser mais explícito sobre o que estou tentando dizer: é que a reforma psiquiátrica, uma vez vitoriosa em sua luta contra a dominação política e na crítica contra as pretensões epistemológicas do discurso psiquiátrico, começa a dar sinais de fastio, a querer se acomodar na suavidade de suas certezas. Pelo contrário, para conjurar um tédio por tudo perigoso, levantamos aqui a suposição de que se torna necessário ultrapassar os limites estreitos de nosso conforto, de nossas 'certezas senso comum', e ousarmos buscar o novo, cair no inominável para além dos limites que a ontologia formal encontra.

Quiçá o esforço atual seja ousar espiritualizar (no sentido bergsoniano) nossas práticas, nossas relações, sem o costumeiro medo do 'enlouquecimento'. Ou melhor, acolhendo e ultrapassando esse medo, uma vez que nesse caso a loucura é um risco real, maior que a mera possibilidade estatística e, talvez, mais do que isso, um risco desejável para aquele que tem a necessidade ética de ser diferente de si mesmo.

Talvez não seja ainda na experiência com os limites - como chegar às fronteiras da loucura sem enlouquecer - que o novo se apresente. $\mathrm{O}$ inominável aparece a partir do momento em que as certezas que nos fazem a vida confortável paradoxalmente não satisfazem mais, nos obrigando ou a obedecer a uma cultura da morte, ou a buscar ultrapassar os limites das crenças mais absolutas. Talvez, nesse momento, a reforma psiquiátrica necessite, afora destruir os asilos e construir novas formas institucionais, empreender um salto sobre um abismo para lá de si mesmo e não apenas se resguardar em volta de limites pretensamente legítimos. 


\section{Da clausura dos corpos à clausura do espírito}

Foi, como dissemos, enfrentando os riscos da ditadura - ou os riscos da 'subversão' - que a reforma psiquiátrica criou seu poder de problematizar a si mesma, abandonar as banalidades de uma medicina cinicamente otimista, tributária e escrava da mesmice em todos os níveis, desde a crença iluminista do século XIX - que ligava a salvação do homem às conquistas tecnológicas - ao conservadorismo que sustentava o Estado que nos fazia inofensivos e cabisbaixos.

Se ultrapassar as banalidades de uma disciplina teórico-prática foi, em parte, o norte que guiou a reforma psiquiátrica até os dias de hoje, não há dúvida de que a banalidade continua a ser, hoje mais do que nunca, nossa grande ameaça. Vivemos a era da banalização, valorizada e desejada como o melhor dos mundos possíveis. Um mundo feito por e para o homem médio. É a vitória da neurose sobre o inominável. É a vitória do que antigamente chamávamos ideal pequeno-burguês, expressando-se tanto na obsessão por segurança - na vida que mantém o controle máximo sobre os riscos de qualquer espécie - quanto na própria idéia de que somos cada vez mais felizes em razão direta da quantidade de opções de consumo a escolher.

Hoje, é o mercado - ou, como diz Forrester (2001), a pseudoeconomia especulativa - quem dita a regra de uma cultura que inventa o prosaico e acessível cidadão comum, sem horizontes para lá da 'sorte' de um salário e de uma aposentadoria - ou da vida com bom senso. Cada vez mais a beleza é coisa para determinadas 'almas nobres', incapazes de suportar o tédio ou de viver sem o direito e o poder da criação - seja de um novo amor, de uma nova música, ou de um novo dia. Em suma, incapazes de suportar uma cultura na qual o dever ético de reivindicar e lutar por liberdade são tratados como anacronismo. Sobre isso Bauman (2000) nos diz que, se a nossa 'civilização' acredita ter conquistado finalmente a liberdade e por isso, ao mesmo tempo, acredita ser inútil pretender mudar qualquer coisa nesse mundo, então "como explicar que entre os louros da vitória (dessa conquista) não esteja a capacidade humana de imaginar um mundo melhor e de fazer algo para concretizá-lo? E que liberdade é essa que desestimula a imaginação e tolera a impotência das pessoas livres em questões que dizem respeito a todos?" (p. 9).

Voltando ao nosso tema - e, na verdade, dele não saímos -, se há um sentido nobre na reforma psiquiátrica, ele não está tão-somente na história da conquista desse poder de se dizer autônomo, de falar sobre si mesmo, a partir de si mesmo, ou de lançar sobre o campo social seu grito, seu discurso como um direito à refutação. Mais do que isso, sua novidade reside na invenção dos instrumen- 
tos para se construir uma sociedade sem manicômios - uma sociedade não-fascista.

O discurso pela sociedade sem manicômios pode ser uma proposição antitética específica contra um modo de se tratar alguém. Mas, para além da extinção das prisões de loucos, não haverá maior contra-senso para a reforma psiquiátrica se ela, principalmente, não combater, também, a extinção das clausuras do espírito. $\mathrm{O}$ risco para esse esquecimento é o paradoxal retorno ao manicômio, disseminado por cada território onde haja a 'liberdade' do bom senso moderno.

\section{Conclusão}

A tarefa mais imediata para a reforma psiquiátrica evitar contra-sensos talvez seja ultrapassar sua obsessão pela organização burocrática - sem esquecê-la, obviamente - e fazer-se expressão do movimento da luta antimanicomial, ou seja, empreender a transgressão hiperbólica, a transgressão da transgressão, e ultrapassar os limites que a ontologia formal encontra. Em outras palavras, superar a própria ontologia formal.

Isso significa transgredir nossa fidelidade à crítica feita às formas, aos produtos; remeter-se ao produtor, ao que chamamos, há pouco, 'causa exemplar' (Lalande, 1999). Ao invés de estarmos preocupados com a forma do produto - a psiquiatria, a doença mental, os manicômios -, nos preocuparmos antes com as 'forças' que geram esse produto. É em resumo o que Foucault, inspirado por Baudelaire, chama estética da existência (Foucault, 1984; 1994). Não mais uma estética da obra, mas uma estética do artista. Assim, se as construções da reforma psiquiátrica (os Centros de Atenção Psicossociais - CAPS) constituem uma obra, embelezá-la - em termos morais, torná-la melhor - não seria a tarefa crítica subjacente à manutenção do status quo? Mas a quem interessa uma reforma psiquiátrica institucionalizada e preocupada em legitimar os seus limites? Isso não seria exatamente criar uma disciplina; ou seja, um dispositivo de 'sujeição' (Portocarrero, 1990)? Será que nos importa uma nova medicina mental concorrente da tradicional? Poderíamos imaginar nossa vida realmente confortável com a mera alternância entre modelos 'cientificistas' de tratarmos as diferenças?

Com certeza não queremos o fim da medicina mental, nem de suas pesquisas biológicas e neuroquímicas sobre a gênese da 'loucura'. Nem se está sugerindo fazer dos CAPS a terra da desrazão. Trata-se tão-somente de uma mudança de prerrogativas. Ao invés de entrarmos na corrida para apenas 'melhorar' os CAPS, exercitar em cada um deles uma maneira de estar no mundo onde viver a contemporaneidade (existência) implique não a resignação perante uma coerção pura (Durkheim, 1991), nem na autolegitimação 
daquilo que Foucault (1998) entende por sujeição, mas em uma tarefa de resistência e subversão que necessariamente se faz sobre um em si que se constitui em sociedade. Se a esse self (si) chamamos produtor (da obra), não o evocamos como um interior a ser decifrado (como faria a psicanálise ou mesmo a psiquiatria), mas como a superfície onde relações se fazem ou se desfazem através de estimulações, para sustentarem objetos antigos (os fatos sociais; a sujeição) ou, de maneira diversa, através de uma agonística de si para consigo, constituindo novos objetos (resistência e subjetivação; estética).

Em outras palavras: se a sujeição é social, lingüística, utilitária, então - como sugere um alter ego de Foucault, Maurice Florence (2001) - para resistir temos antes de problematizar ao mesmo tempo as 'práticas' pelas quais um modo de agir e pensar fornece inteligibilidade para a constituição correlativa do sujeito e do objeto; e as relações de poder, enquanto determinantes dos diferentes modos de objetivação do sujeito.

Por fim, com a estética da existência (subjetivação), teríamos o exercício daquilo que Foucault chama liberdade, ou seja, a efetuação das práticas pelas quais os homens se constituem (enquanto sujeitos - incluindo a idéia de 'sujeito coletivo') como determinantes de um modo singular de objetivação de si mesmo (enquanto correlato objetivo desse sujeito).

Talvez para tornar nossa vida bela, e nesse sentido livre, precisamos de alguma forma limitar a hegemonia das preocupações utilitárias, ou seja, torná-las secundárias diante de uma preocupação estética; a uma motivação quase metafísica de transcender as próprias determinações do campo social, político e econômico. Precisamos, enfim, de uma reforma psiquiátrica do tamanho de uma nova teoria do sujeito (para produzirmos outros objetos - ao menos não tão deploráveis como o 'louco psiquiatrizado'); que não seja substancial ou temática, eivada de significado conforme o significante, mas, como diria Guattari (1996), 'a-significante' e relacional. Uma reforma também sem significado a priori, transgressora de si mesma. Um tipo de transgressão que não mais hesita em ultrapassar o cotidiano, a medianidade, a resignação do homem banal ou neurótico, coagido pelos fatos sociais; uma transgressão que também é, de certa maneira, a própria loucura. 


\section{REFERÊNCIAS BIBLIOGRÁFICAS} Althusser, Louis
2001

Amarante, Paulo (org.) 1998

Arendt, Hanna 1999

Barthes, Roland 2001

Barthes, Roland 1971

Bauman, Zygmunt 2000

Bergson, Henri 1990

Deleuze, Gilles;

Guattari, Felix s.d.

Detienne, Marcel 1988

Durkheim, Emile 1991

Forrester, Vivianne 2001

Foucault, Michel 2001

Foucault, Michel 1996

Foucault, Michel 1994

Foucault, Michel 1990

Foucault, Michel 1984

Foucault, Michel 1975

Florence, Maurice 2001

Guattari, Felix; Rolnik, Suely 1986

Guattari, Felix 1972
Aparelhos ideológicos de Estado.

Lisboa: Paz e Terra.

Loucos pela vida: a trajetória da reforma psiquiátrica no Brasil.

Rio de Janeiro: Ed. Fiocruz.

Eichmann em Jerusalém: um relato sobre a banalidade do mal. São Paulo: Companhia das Letras.

Elementos de semiologia.

São Paulo: Cultrix.

Sade, Fourier, Loyola.

Paris: Ed. du Seuil.

Em busca da política.

Rio de Janeiro: Jorge Zahar.

Matéria e memória.

São Paulo: Martins Fontes.

O anti-Édipo: capitalismo e esquizofrenia I.

Lisboa: Assírio \& Alvim.

Os mestres da verdade na Grécia arcaica.

Rio de Janeiro: Jorge Zahar.

A divisão do trabalho social.

Lisboa: Presença.

Uma estranha ditadura.

São Paulo: Ed. Unesp.

Ditos $\mathcal{E}$ escritos, III. Estética: literatura e pintura, música e cinema.

Rio de Janeiro: Forense Universitária.

O anti-Édipo: uma introdução à vida não fascista. In: Cadernos de subjetividade (número especial sobre Gilles Deleuze). Pelbart, P. P.;

Rolnik, S. (org.) São Paulo: Núcleo de Estudos e Pesquisas da

Subjetividade, Programa de Estudos de Pós-Graduados da PUC/SP.

Dits et écrits. v. IV.

Paris, Gallimard.

Tecnologias del yo.

Barcelona, Paidós.

Histoire de la sexualité. II. l'usage des plaisirs.

Paris, Gallimard.

Surveiller et punir: naissance de la prison.

Paris, Gallimard.

Foucault. In: Huisman, Dennis (org.) Dicionário dos filósofos.

São Paulo: Martins Fontes.

Micropolítica: cartografias do desejo.

Petrópolis: Vozes.

Psychanalyse et transversalité.

Paris: Maspero. 
Kant, Immanuel

1987

Lalande, André 1999

Nietzsche, Friedrich

Wilhelm

1994

Portocarrero,

Vera Maria

1990

Serra, Antônio

1981
Crítica da razão pura.

São Paulo: Nova Cultural.

Vocabulário técnico e crítico da filosofia.

São Paulo: Martins Fontes.

Assim falou Zaratustra: um livro para todos e para ninguém.

Rio de Janeiro: Bertrand Brasil.

O dispositivo da saúde mental: uma metamorfose na psiquiatria brasileira. Rio de Janeiro, IFCS/UFRJ, tese de Doutorado.

A psiquiatria como discurso político.

Rio de Janeiro: Achiamé.

Recebido para publicação em junho de 2003.

Aceito para publicação em setembro de 2003. 